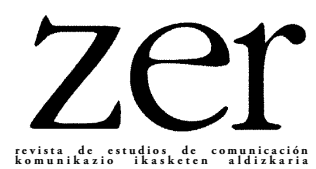

\title{
Sex Education (Netflix): representación de adolescentes LGTBIQ+ como recurso dramático
}

\author{
Sex Education (Netflix): LGTBIQ+ nerabeen irudikapena baliabide \\ dramatiko gisa
}

\section{Sex Education (Netflix): representation of LGTBIQ+ Teenagers as Dramatic Resource}

\author{
Águeda María Valverde Maestre ${ }^{1}$, José Patricio Pérez Rufi² ${ }^{2 \star}$ \\ ${ }^{1}$ Universidad de Córdoba, ${ }^{2}$ Universidad de Málaga
}

\begin{abstract}
RESUMEN: La evolución de los hábitos de consumo de los espectadores televisivos explica la renovación de sus intereses como objetos de estudio. Entre las tendencias actuales, se encuentra la creación de producciones propias por las plataformas $\mathrm{VoD}$, destacando las series de ficción protagonizadas por adolescentes. Este estudio analiza la representación de los adolescentes pertenecientes a la comunidad LGTBIQ+ en una serie original de Netflix, Sex Education, destacada por la diversidad en la tipología de sus personajes. Los resultados concluyen que incluso si la intención de la serie es la representación de la diversidad en las identidades, parte de la presentación de estereotipos.
\end{abstract}

PALABRAS CLAVE: género; queer; adolescentes; serie; televisión; Netflix.

ABSTRACT: The evolution of television viewers' consumption habits explains the renewal of their interests as objects of study. One of the current trends is the production of original contents by VoD streaming platforms, where fiction series starring teenagers stand out. This paper analyzes the representation of teenage characters belonging to the LGTBIQ+ community in a Netflix original series, Sex Education. This series stands out for the diversity in the typology of its characters. The results conclude that even if the intention of the series is to represent diversity in the characters' identities, the series is based on presenting stereotypes.

KEYWORDS: gender; Queer Theory; teenagers; television series; Netflix.

\footnotetext{
* Correspondencia a / Corresponding author: José Patricio Pérez Rufí. Facultad de Ciencias de la Comunicación. Calle León Tolstoi, s/n. Campus Teatinos (29071 Málaga) - z02vamaa@uco.es - https://orcid.org/0000-0002-7084-3279

Cómo citar / How to cite: Valverde Maestre, Águeda María; Pérez Rufí, José Patricio (2021). "Sex Education (Netflix): representación de adolescentes LGTBIQ+ como recurso dramático", Zer, 26(50), 167-184. (https://doi.org/10.1387/zer.22528).

Recibido: 09 febrero, 2021; aceptado: 22 abril, 2021.

ISSN 1137-1102 - eISSN 1989-631X / (c) 2021 UPV/EHU
}

(i) $\odot$ Esta obra está bajo una Licencia

Creative Commons Atribución-NoComercial-SinDerivadas 4.0 Internacional 


\section{Introducción}

La industria audiovisual puede comprenderse como un ecosistema comunicativo en permanente evolución y en constante creación de nuevos contenidos y de sus consiguientes universos simbólicos. En el ámbito televisivo, los hábitos de consumo de los espectadores han evolucionado hacia modelos de distribución de contenidos audiovisuales basados en el uso de las redes telemáticas, en detrimento de la televisión lineal.

Las nuevas plataformas de distribución de contenidos audiovisuales han venido, además, acompañadas de la apuesta por la producción propia con objeto de ofrecer contenidos exclusivos, al tiempo que de prescindir de la compra de licencias de otras compañías (potencialmente rivales). Las producciones originales de Netflix están además fuertemente ligadas a su identidad de marca, como elemento completamente transversal dentro de la estrategia de la marca Netflix (Mayorga-Escalada, 2019).

Según publicaba la Federación de Cines de España (FECE) (2019), el 80\% de los menores de 25 años declara tener una suscripción a una plataforma de vídeo digital, donde, sobre todo, consumen series. Las plataformas VoD cuentan con perfiles muy definidos y producen contenidos específicos destinados a estas audiencias. Estas producciones orientadas hacia un perfil de audiencia joven, sin embargo, atraen distintas franjas de edad. «El teen ya no es de 13 a 19. Se empieza a ser maduro a partir de los 45 pero se empieza a ser joven a los 16» (Guarinos-Galán, 2009: 205). Es así como el sector del entretenimiento demuestra su interés en los «fenómenos teenagers» (Guarinos-Galán, 2009: 204), desarrollando productos artísticos que toman al adolescente como motivo central.

Estas series, sus temáticas y las perspectivas desde las que son abordadas se suponen sensibles a los intereses de los adolescentes y los jóvenes adultos, al tiempo que influyen en la construcción del imaginario de la audiencia y en sus valores, como «constructoras de universos simbólicos» (López-Gutiérrez \& Nicolás-Gavilán, 2015: 23). En este sentido, Pereira (2009: 41) sostiene que, como obra cultural no neutra, «contribuye igualmente a construir la identidad personal y, más en concreto, la identidad de género». Raya, Sánchez-Labella y Durán (2018: 132-133) afirman que la representación de los personajes y el recurso a estereotipos tienen una función socializadora para el público adolescente, por cuanto «supone un acercamiento a partir del cual éste experimenta y reflexiona. Por ello, es importante controlar cómo se construyen los personajes».

Este trabajo explora la representación de los personajes adolescentes pertenecientes a la comunidad LGTBIQ+ en un relato audiovisual contemporáneo representativo de la producción propia de las plataformas $\mathrm{VoD}$, en concreto, las dos temporadas de la serie original de Netflix Sex Education (2019-2020). Así, esta investigación tiene como objetivo principal analizar los personajes adolescentes pertenecientes a la comunidad LGTBIQ+ y categorizar la posible tipología que se haga de 
los mismos, con objeto de evaluar el mensaje transmitido desde el análisis de contenido y de representación de género.

Argumentamos la elección de esta producción, en primer lugar, por la popularidad de la plataforma Netflix entre la audiencia juvenil, así como por su interés desde el análisis de contenido y desde un enfoque de género (Pérez-Lence, 2019). Como ocurre con las películas de Almodóvar, la presentación de los personajes hace de la serie un «elemento perfecto para hacer un análisis queen» (Pelayo, 2011: 162).

La hipótesis de la que parte este trabajo es que Sex Education hace de la diversidad y de la voluntad de atención a diferentes sensibilidades e identidades queer su objetivo a la hora de representar a los diferentes personajes. Inicialmente, estas intenciones terminan por llevar a la configuración de estereotipos y de fórmulas narrativas habituales en la comedia, como género condicionante del conjunto de las categorías narrativas del discurso, si bien el posterior desarrollo dramático basado en la exploración de la identidad de los personajes los aleja de los estereotipos. Queremos demostrar que la creación de personajes queer responde a la necesidad de crear conflicto en el plano dramático, por lo que supone un recurso al servicio de la acción dramática.

Entendemos por recurso dramático aquellos nodos de acción o de información transmitidos por el discurso que hilvanan el relato, desarrollando así el drama, el conflicto y la evolución de la situación que experimenta un personaje en una narración. Los recursos dramáticos en la serie de televisión permiten que el relato evolucione, que tenga un desarrollo narrativo, y que mantenga el interés de los espectadores. Basté y Peralta (2016) llegan a titular su manual sobre guion «Sorprender cada minuto y medio», destacando la demanda constante de «llamadas de atención» por parte del espectador para que lo mantengan pendiente del desarrollo de la trama. Consideramos que Sex Education hace de la construcción de sus personajes desde una perspectiva de género y de orientación sexual un uso propio de un recurso dramático, como pretendemos demostrar a través del análisis de contenido.

La serie analizada se inscribe en el género de la comedia. El género, en este caso la comedia, condiciona la construcción de personajes: Pérez-Rufí (2017) señala que la configuración de los caracteres en términos de verosimilitud y complejidad quedan condicionados por el género del discurso audiovisual, al punto de que la comedia (clásica de Hollywood, en su caso) suele articular con mayor frecuencia personajes planos antes que redondos.

Los estereotipos aparecen con mayor frecuencia en comedia (Galán-Fajardo, 2006), por lo que los valores transmitidos también son más evidentes desde una perspectiva de género. Toledano y Verde (2007) apuntan que los estereotipos son recreaciones mentales de una imagen en relación a un grupo de personas que comparten características. López y Cobeaga (en Ríos San Martín, 2012) ligan igualmente 
la comedia con la presencia de personajes creados desde estas fórmulas (aunque lo denomina «arquetipos»).

Los antecedentes a la investigación remiten necesariamente a la Teoría Queer y a los textos fundacionales en este enfoque metodológico de Lauretis (1991) y Butler (2007), además de otros estudios críticos y de referentes en los estudios queer y de género como Tovar (2019), Solana (2013) o Zurian-Hernández y Herrero-Jiménez (2014). En cuestiones metodológicas y de articulación narrativa del relato, resultan imprescindibles las menciones a los trabajos de Galán-Fajardo (2006, 2007) y Casseti y Di Chio (1990), además de Raya, Sánchez-Labella y Durán (2018) y GuarinosGalán (2009), de forma más específica con respecto a las investigaciones acerca de la representación de adolescentes en series de televisión.

Zurian-Hernández y Herrero-Jiménez (2014) reivindican la teoría filmica feminista y de los estudios de género como un marco teórico competente y como enfoque adecuado para la investigación en comunicación audiovisual. El enfoque metodológico más adecuado a nuestros objetivos y objeto de estudio toma base en la Queer Theory (o Teoría Queer). Apunta Tovar (2019: 66) que Lauretis introduce el término Queer Theory como parte de los Estudios Gays y Lésbicos donde se desarrollan «problemas en torno a la sexualidad y la diferencia sexual develados inicialmente por las feministas y desarrollados por los teóricos gays y lesbianas, pero con un fuerte ascendiente del llamado posestructuralismo». Sostenemos que la innovación en las representaciones narrativas de los distintos géneros y sexualidades resulta necesaria para combatir los tópicos, la desinformación y el aprendizaje erróneo acerca de esta realidad, así como el análisis de estas representaciones.

Los textos de Judith Butler sobre Teoría Queer sostienen que la dualidad de los sexos estaría ligada a la normatividad heterosexual que llega a cuestionarse, incluso difumina gradualmente, la consideración y demanda de la homosexualidad (Collin, 2010: 178). Según Butler, el sexo (no el género) es de por sí una construcción cultural (Butler, 2007: 287). La Teoría Queer sostiene que la identidad «es una construcción social que debe entenderse como parte de un proceso abierto y cambiante, siempre sensible a transformaciones y redefiniciones» (Pelayo-García, 2011: 161), al tiempo que reniega de las restricciones «culturales y heterodominantes» (Hernández-Escorcia, 2020: 2) rechazando clasificaciones como varón, mujer, homosexual, bisexual o transexual.

Martínez (2015: 14) reclama la necesidad de «someter a debate la categoría sexo, como ocasión privilegiada para reformular las múltiples conceptualizaciones que involucran la dimensión del cuerpo». La Teoría Queer, limitada por las categorías actuales, afirma, «ha demostrado potencialidad para cuestionar los supuestos ontológicos que operan en torno al sexo».

Solana (2013) señala que, con todo, la Teoría Queer contiene errores, dado «su afán por analizar, justificar y reivindicar no a una sino a toda una serie de prácticas e 
identidades que provenían de parámetros rígidos de lo considerado normal en términos de género y sexualidad» (Solana, 2013: 72). Solana (2013: 87) añade que la Teoría Queer no está a favor o en contra de ninguna postura y no es un manual político para definir las identidades de género, sino una iniciativa versátil que debe renovarse junto al avance de las concepciones relacionadas con la comunidad LGTBIQ+. La innovación en las representaciones narrativas de los distintos géneros y sexualidades resulta necesaria para combatir los tópicos, la desinformación y el aprendizaje erróneo acerca de esta realidad.

En los últimos años los programas pertenecientes al género del entretenimiento fueron los más consumidos por los espectadores de televisión en España (Valverde-Maestre, 2019), con temáticas vinculadas a los intereses de la sociedad. Consideramos que el estudio de la representación de la comunidad LGTBIQ+ en la ficción seriada televisiva puede actualizar tanto las metodologías como las conclusiones acerca de la representación de las identidades queer en los contenidos de ficción de mayor consumo entre la audiencia juvenil.

\section{Metodología}

El análisis de la representación de los personajes en un relato audiovisual implica el análisis de contenido, donde destacan los modelos relacionados con las perspectivas de la narrativa filmica. Según Casetti y Di Chio (1990), los personajes son un elemento distintivo para el análisis narrativo de una obra: son los creadores y desarrolladores de la trama. Este interés por el análisis de personajes se justifica también desde el enfoque de género de este trabajo.

Entre los numerosos modelos de análisis, el estudio de los personajes puede ser orientado desde tres perspectivas en función de si el personaje es analizado como persona (enfoque fenomenológico), como rol (enfoque formal) o como actante (enfoque actancial) (Casetti \& Di Chio, 1990: 172-173).

Tomamos en consideración la metodología propuesta por Guarinos-Galán (2009) para el análisis de series protagonizadas por adolescentes. Tomamos de este modelo un primer apartado que denominamos fase previa del análisis donde recogemos información relativa a la producción analizada: título, género, número de temporadas, número de episodios, duración de cada episodio, años de producción y fechas de estreno en Netflix, creadores, productoras, responsables de la dirección, reparto y breve sinopsis.

Nuestra metodología de análisis del personaje se apoya igualmente en la propuesta de Galán-Fajardo (2007), estructurada a partir de tres dimensiones del personaje: física, psicológica y social. Siguiendo el modelo de caracterización de Galán-Fajardo, el diseño de la ficha de personajes podría seguir el esquema básico establecido para el proceso de caracterización ya empleado en la literatura y que ya recogía Egri (1946) y otros autores posteriores, a partir de tres grandes ejes: 1) Dimen- 
sión fisica, con aquella información relativa a los rasgos externos de los personajes: nombre, edad, aspecto fisico, etnia y sexo, "con la finalidad de proporcionar información sobre su fisionomía o manera de vestir» (Galán-Fajardo, 2006: 66). Incluimos en este apartado una categoría relativa al género, por cuanto consideramos que una perspectiva de análisis queer debe atender también a cuestiones que van más allá del sexo y que implica la mención al género; 2) Dimensión psicológica, desglosada en tipo de personalidad, temperamento y objetivos/metas, según las categorías propuestas por Galán-Fajardo (2006), que divide la personalidad en dos tipos: extrovertida e introvertida, además de identificar cuatro tipos de temperamentos: intuitivo, perceptivo, reflexivo y sensitivo; y 3) Dimensión social, que describe el entorno del personaje y que dividimos en clase social, estabilidad en las relaciones, estado civil, ámbito familiar (hijos), ámbito profesional o de formación.

Ampliamos esta metodología con un cuarto apartado, que denominamos aspectos narrativos, y que se inspira en el análisis de estereotipos y temas de Galán-Fajardo (2006), donde introducimos otras categorías. Este apartado implica la atención a otros aspectos narrativos, como la temática de la serie y las circunstancias de cada capítulo. Puede aplicarse a personajes principales, secundarios y episódicos. En nuestro caso, incluimos las siguientes categorías: rol en el relato, posición jerárquica dentro de la narración (personajes protagonistas, principales, secundarios o episódicos), aspectos negativos relacionados con su identidad y rol representado dentro de la diversidad de la comunidad LGTBIQ+. Las cuestiones narrativas vienen irremediablemente ligadas a las tres dimensiones anteriores (muy especialmente en los objetivos o metas dentro de la dimensión psicológica), si bien consideramos que estas cuestiones merecen ser deslindadas por cuanto implican directamente a la perspectiva queer de este análisis de personajes.

El quinto apartado de este análisis atiende a lo que Galán-Fajardo (2006: 72) denomina la actitud del personaje, desde la que atenderemos al modo en que cada personaje afronta las circunstancias de las que participan en el relato. Añadimos en este apartado cuestiones relativas a lo que Galán-Fajardo denomina análisis de temas, seguido del análisis de conflictos.

Mencionamos la evolución de la caracterización del personaje como recurso dramático en la discusión de resultados, sirviéndonos de la interpretación y de la crítica del discurso.

\section{Resultados}

En julio de 2020, Netflix contaba con al menos 110 series de ficción originales, 33 de ellas protagonizadas por personajes adolescentes y por jóvenes. De éstas, al menos 12 cuentan con personajes cuyas identidades podrían identificarse con diversos perfiles de la comunidad LGTBIQ+. Sex Education, como hemos afirmado, destaca dentro del conjunto de las series de Netflix protagonizadas por adolescentes. 
TABLA 1

Fase previa de análisis

\begin{tabular}{l|l}
\hline Título y plataforma & \multicolumn{1}{c}{ Sex Education (Netflix) } \\
\hline Género & Comedia \\
\hline Temporadas & 2 \\
\hline N. ${ }^{\circ}$ episodios & 16 (8 cada temporada) \\
\hline Duración episodio & 45 minutos \\
\hline Años de producción & $2019-2020$ (actualmente en producción) \\
\hline Estreno en Netflix & $11 / 01 / 2019$ (temporada 1); 17/01/2020 (temporada 2) \\
\hline Creadora & Laurie Nunn \\
\hline Productoras & Eleven Film, Netflix \\
\hline Nacionalidad & Reino Unido \\
\hline Directoras & Kate Herron, Ben Taylor, Alice Seabright, Sophie Goodhart \\
\hline Reparto/personaje & $\begin{array}{l}\text { Asa Butterfield (Otis Milburn), Emma Mackey (Maeve Wiley), Aimee Lou } \\
\text { Wood (Aimee Gibbs), Gilian Anderson (Jean Milburn), Ncuti Gatwa (Eric } \\
\text { Effiong), Connor Swindells (Adam Groff), Kedar Williams-Stirling (Jackson } \\
\text { Marchetti), Tanya Reynolds (Lily Iglehart), Patricia Allison (Ola Nyman), Cha- } \\
\text { neil Kular (Anwar), Sami Outalbali (Rahim). }\end{array}$ \\
\hline Sinopsis & $\begin{array}{l}\text { Otis Milburn, un adolescente virgen, explora su sexualidad con ciertas dificul- } \\
\text { tades. Su madre, la reputada sexóloga Jean Milburn, y su alrededor, dificultan al } \\
\text { protagonista su misión. Otis adopta el rol de sexólogo aficionado en su instituto, } \\
\text { encontrándose con todo tipo de casos y problemas en el ámbito sexual entre sus } \\
\text { compañeros. }\end{array}$ \\
\hline Fing
\end{tabular}

Fuente: elaboración propia.

Con al menos una tercera temporada confirmada para su producción, la serie británica Sex Education consta hasta ahora de dos temporadas de ocho episodios cada una. Este análisis tomará como referencia cinco personajes pertenecientes a la comunidad LGTBIQ+ presentes en el relato. La serie incluye otros tres personajes LGTBIQ+ que no incluimos en el análisis: Anwar (Chaneil Kular), personaje abiertamente homosexual líder de la pandilla denominada «Los Intocables», Tanya (Alice Hewkin) y Ruthie (Lily Newmark), pareja de mujeres lesbianas con apariciones episódicas en tres episodios. Excluimos a estos tres personajes por cuanto apenas es comunicada información sobre ellos, dada su escasa relevancia en el relato. Del lado de los personajes adultos, como modelo de personaje que no incluimos por su edad, descartamos también el análisis de dos mujeres que mantienen una relación en principio estable, Sofia Marchetti (Hannah Waddingham) y Roz Marchetti (Sharon DuncanBrewster), madres del estudiante Jackson Marchetti (Kedar Williams-Stirling). 


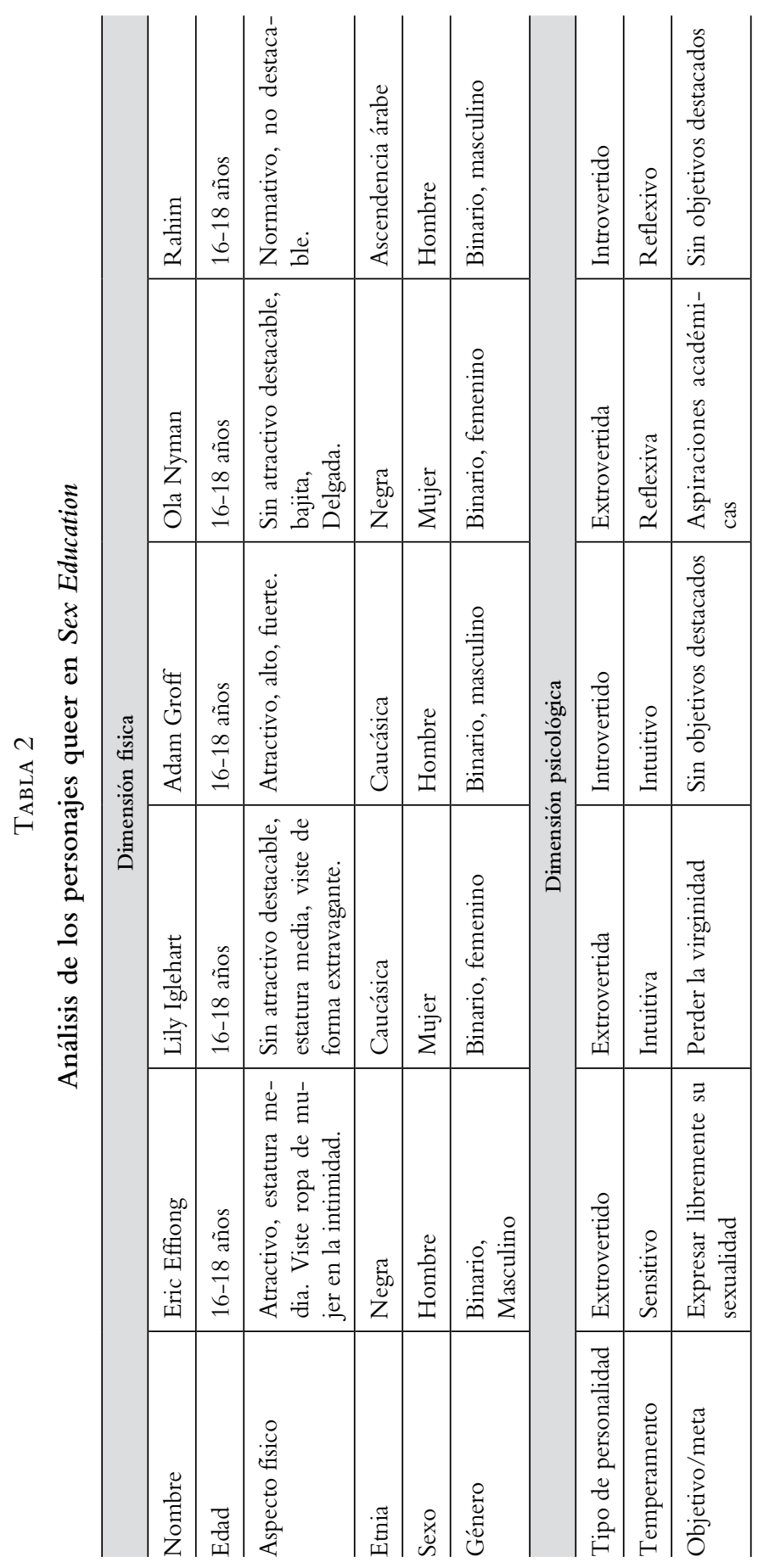




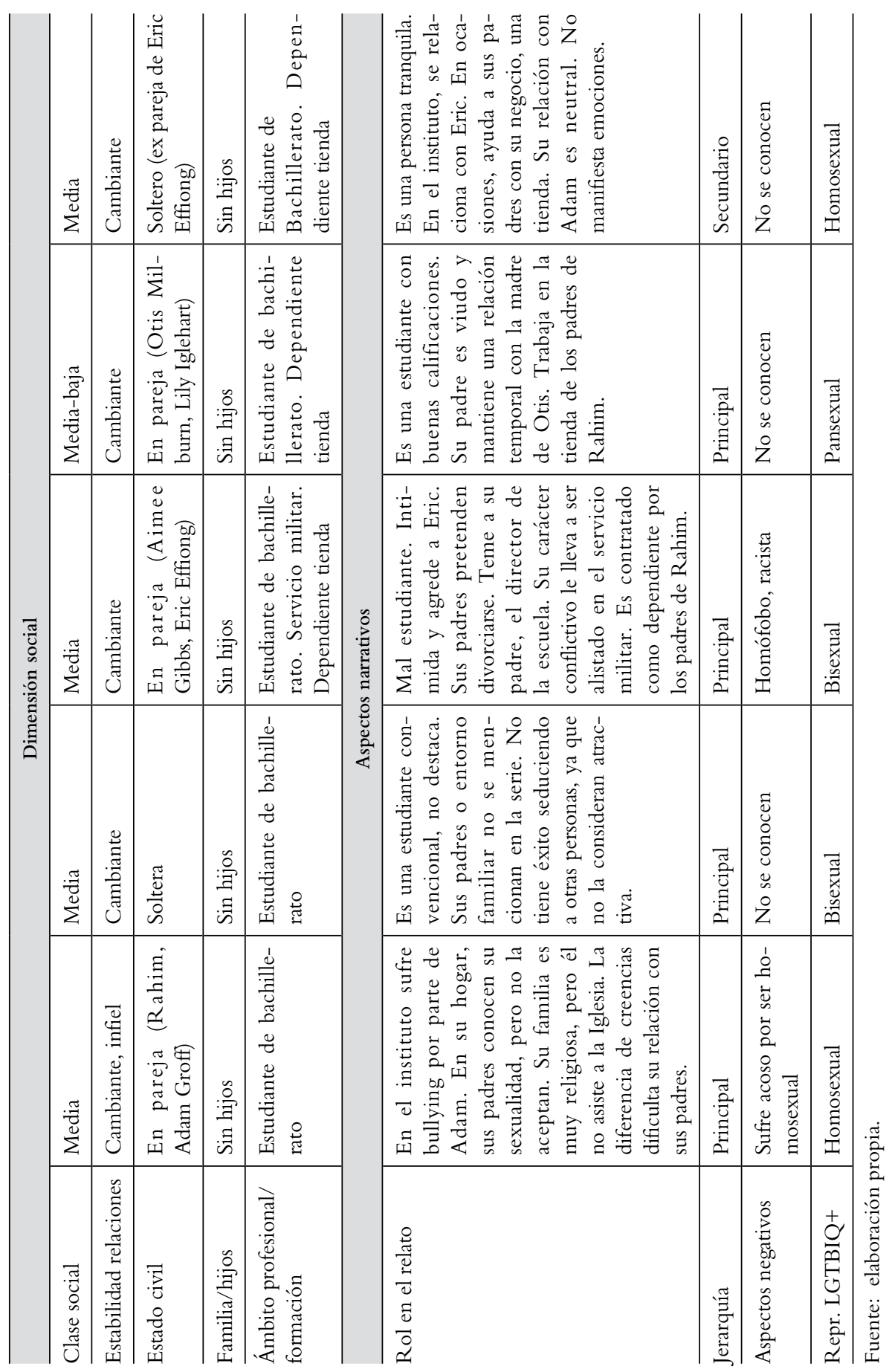


Pasamos a continuación a comentar de forma independiente en cada uno de los personajes las cuestiones relativas a la actitud del personaje, el análisis de los temas que abordan sus tramas y de los conflictos a los que se enfrentan.

Eric Effiong es el mejor amigo de Otis, el protagonista de la serie. Es una persona abierta y divertida, que disfruta vistiéndose de mujer. Su relación con sus padres es delicada, ya que aceptan, pero no comparten la homosexualidad y la distancia de su hijo respecto a la Iglesia católica. Sus padres ocultan la sexualidad de su hijo frente al resto de la familia, aunque muestran un enorme aprecio hacia el joven.

Eric adopta en el instituto una actitud miedosa y pasiva ante su acosador, Adam. A nivel íntimo, tiene un apetito sexual destacable. Mantiene una relación tranquila, cerrada y pública con Rahim, un estudiante francés de ascendencia musulmana. Le es infiel a Rahim cuando Adam flirtea con él. A lo largo del relato, Eric termina su relación con Rahim y comienza un romance secreto con Adam. Mantiene una relación estrecha con él. Por el contrario, adopta una actitud miedosa y estática ante su acosador, Adam.

En cuanto a los temas que abordan las tramas de Eric, destaca por encima de todos el cuestionamiento de su identidad como homosexual, conocida públicamente, ligada a su carácter extrovertido y a su muy singular apariencia física. Otras cuestiones relacionadas con Eric tienen que ver con la infidelidad, la pertenencia a un colectivo marginado por su etnia, la religión y las agresiones físicas dentro de un espacio de formación (bullying). Los conflictos de Eric se derivan de las temáticas en las que se implica en el relato: identidad pública, conflictos amorosos e infidelidad.

Lily Iglehart trata de mantener relaciones sexuales con la mayoría de los personajes que aparece en el relato. Otis rechaza su propuesta, entablando una relación de amistad. Los estudiantes declinan su oferta, tanto por no considerarla atractiva como por tener una sexualidad diferente. Lily es un personaje extravagante que podría identificarse con el nerd en el cine adolescente. Según López Rodríguez (2011: 807), los términos nerd o geek remiten a «un cierto tipo de persona caracterizada por su alta capacidad intelectual, por sus pobres habilidades sociales y por una gran dedicación a sus aficiones, ya sean la informática, los cómics o los videojuegos». En el instituto, Lily pertenece al grupo de amigos de Otis y Eric. Desarrolla vaginismo tras su primera relación sexual con un estudiante varón.

Lily es besada por una mujer, Ola. Al principio, la rechaza, manifestando homofobia y disgusto hacia las relaciones con personas de su mismo sexo. Sin embargo, termina aceptando su inclinación por las mujeres, comenzando una relación sentimental con Ola. 
El personaje de Lily plantea temas como el cuestionamiento de la sexualidad normativa, las parafilias sexuales, como aficionada a dibujar sus fantasías relacionadas con extraterrestres y personas pertenecientes al ámbito del cosplay en un cuaderno, además de exponer cuestiones relativas a salud sexual como el vaginismo. Los conflictos nacen de sus problemas de aceptación de sí misma, que derivan en conflictos amorosos y sexuales: se enfrenta al rechazo sufrido por su físico y la falta de aceptación de sí misma y de autoestima, además de cuestionar su sexualidad y no sentirse identificada con los paradigmas normativos en cuanto a género y sexualidad socialmente aceptados, declarándose bisexual.

Adam Groff es presentado en los primeros episodios como el acosador de Eric, personaje abiertamente homosexual. Adam es homófobo y desea ver reconocido su rol autoritario, aunque es infeliz. En ese momento, Eric es la pareja de Aimee. En el acoso contra Eric, Adam descubre que se siente atraído por aquel y terminan manteniendo relaciones sexuales. Tras abandonar la escuela, ingresa en el servicio militar. Tras ser expulsado de la academia militar, trabaja como dependiente.

Su relación con Eric evoluciona en secreto, hasta que éste argumenta que no quiere estar con una persona que sienta vergüenza o rechazo. Adam trata de modificar su personalidad, haciendo público su vínculo con Eric.

El personaje de Adam aborda temas como la homosexualidad, la homofobia, las agresiones físicas y la violencia de género. Los conflictos nacen de su actitud y de las temáticas abordadas: a nivel amoroso, trata la insatisfacción de una relación no deseada. En los espacios formativos (el instituto), desarrolla su enfrentamiento y abuso de poder contra Eric, manifestando su falta de aceptación consigo mismo por medio de violencia. A nivel familiar, el conflicto es con sus padres, en proceso de divorcio.

Ola Nyman en los primeros episodios mantiene una relación sentimental con Otis, el protagonista de la serie. Adopta una actitud celosa hacia Maeve y la considera su enemiga. La incompatibilidad de caracteres lleva a Ola a terminar la relación con Otis. Tras abandonar esta relación, Ola se declara pansexual y expresa sus sentimientos por Lily. Tras ser rechazada por Lily, termina por establecer una relación con ella. Su personalidad es alegre y divertida, opuesta a Otis. Está en contra del sexismo que reconoce en obras artísticas y literarias.

En cuanto a las temáticas que le implican, el personaje de Ola plantea cuestiones como la homosexualidad, el duelo ante la muerte y el sexismo. Los conflictos serán de naturaleza amorosa, expresados a través de los celos ante otra mujer, así como sexuales. Como en el caso de Lily, Ola no se identifica con modelos paradigmáticos de género y sexualidad y termina por identificarse como pansexual. Los conflictos laborales la ponen en relación con Adam, con quien empatiza al compartir problemas similares. 
Rahim es un personaje secundario presentado en la primera temporada como pareja de Eric, con el que mantiene una relación sentimental públicamente conocida y cerrada. Sin embargo, Eric le será infiel con su acosador, Adam, sin que Rahim sea consciente de la traición. Su personalidad se define desde la adopción de un rol de absoluta discreción: evita el conflicto y no quiere ser el centro de atención de los demás.

Aunque se trata de un estudiante procedente de un programa de intercambio, su origen extranjero no condiciona el desarrollo de las tramas que lo implican. Los temas que plantea vienen ligados a los de Eric, abordando cuestiones como la homosexualidad y la infidelidad que sufre. Los conflictos serán de naturaleza amorosa, al estar relacionados con su relación con Eric y con su infidelidad.

El comentario de la situación de cada personaje nos lleva también a destacar que tanto los objetivos como sus roles en el relato apuntan hacia el conflicto y la evolución de los personajes. Los problemas de los personajes están intrínsecamente relacionados con su dimensión psicológica y social, pero de forma más específica con su identidad de género o su orientación sexual. Los objetivos de Eric o Lily vienen de la mano de la expresión de su deseo sexual. Adam entra en conflicto con la estricta moralidad en la que ha sido educado. Ola investiga sus tendencias y Eric, como Adam aunque en otras circunstancias, también entra en conflicto con su entorno familiar y sus creencias religiosas a cusa de orientación sexual. En estos personajes la raíz del drama está por lo tanto en su orientación sexual o en su identidad de género y el conjunto de sus caracterizaciones gira en torno a ello.

\section{Discusión de resultados}

El cómputo de las series de ficción adolescente producidas por Netflix demuestra la importancia de la inclusividad del colectivo LGBTIQ+ en su catálogo. Doce de las veintiuna obras pertenecientes a esta categoría presentan al menos a un personaje con estas características. Las series de adolescentes de Netflix muestran una sensibilidad hacia los personajes queer y los incluyen entre sus caracteres con frecuencia. Proponemos la investigación de la diversidad en cuanto a identidades de género o étnicas en el catálogo de Netflix para futuros trabajos.

Las tramas, temáticas y conflictos tratados en las dos temporadas de Sex Education pretenden representar los intereses y las preocupaciones del público adolescente, juvenil y «adultescente» al que se dirige. En esta obra, los personajes pertenecientes a la comunidad LGTBIQ+ participan tanto en la trama principal como en las subtramas. Hemos de apuntar, sin embargo, que a pesar del número de personajes principales y de tramas centrales en las que se implican los personajes queer, en la serie hay dos personajes heterosexuales binarios que destacan por encima de todos los demás 
y que son los verdaderos protagonistas de la serie: Otis Milburn (Asa Butterfield) y Emma Mackey (Maeve Wiley).

Las características físicas de estos personajes son variadas. Su apariencia, su etnia y su sexo son dispares. Sin embargo, pertenecen a un grupo de edad común, entre dieciséis y dieciocho años, como compañeros de un mismo instituto: como en tantas series, el espacio compartido articula las relaciones entre personajes. Dado que la mayor parte de sus personajes son adolescentes, se explica que la mayor parte de los personajes queer presentados se integren el perfil del joven estudiante. Aunque no hemos atendido a la presencia de personajes LGTBIQ+ entre los adultos, sí aparecerían representados en la pareja conformada por las madres de Jackson Marchetti.

Apuntemos que dos de los cinco adolescentes queer de la serie, Eric y Lily, hacen de la excentricidad en su apariencia externa uno de sus rasgos caracterizadores. Estos personajes manifiestan así, a través de su aspecto físico, la disidencia con los cánones estéticos imperantes. Apuntábamos que Lily era representada como una nerd, de la misma forma que Eric es el homosexual que se traviste (siendo por ello objeto de acoso para otros personajes), definido también conforme al estereotipo de gay afeminado.

Según Galán-Fajardo (2006: 59), «los guionistas (...), a menudo, buscan personajes simples o rápidamente reconocibles por el público, para conseguir que el proceso de identificación sea lo más rápido posible». La repetición de estos esquemas propicia la aparición de estereotipos o tópicos en la construcción de los personajes, con ventajas como su funcionalidad en la descripción de ideas pero con inconvenientes derivados de su naturaleza generalista y discriminativa (Galán-Fajardo, 2006). El recurso a estereotipos en estos casos permite a los espectadores reconocer y ubicar al modelo de personaje propuesto con pocas pinceladas, como parte de la funcionalidad narrativa del estereotipo, si bien arrastra consigo los prejuicios y los tópicos asociados a estos estereotipos de personajes.

Ocurre, sin embargo, que el desarrollo del relato depara sorpresas en este sentido y permite que los personajes «crezcan» y evolucionen para ganar en matices, rasgos contradictorios que los llenan de volumen y que los convierten en personajes redondos. Así, Eric es víctima de sus propias contradicciones como persona religiosa en una familia tradicional, enfrentado a la duda de ser quien quiere ser o quien espera el resto de la sociedad que sea. La forzada relación con su acosador también se convierte en un factor que introduce contraste en su caracterización, a la que se suma la inquietud que le provoca la infidelidad.

De la misma forma, Lily evoluciona de forma paralela al desarrollo de la serie y gana progresivamente en protagonismo para terminar conformando un personaje complejo y contradictorio que lleva sus problemas relativos a sexo y género a cues- 
tiones más personales que alcanzan a otras facetas de su vida, como sus aficiones, su creatividad o su vocación profesional.

La personalidad de los personajes analizados, así como su temperamento, sus objetivos o sus metas son diversos y responde a la voluntad de representación de la diversidad que pretende adoptar la serie. Las relaciones sociales de los caracteres queer, en especial en el ámbito amoroso, son cambiantes, en su mayoría. Este rasgo puede interpretarse de dos formas: en primer lugar, relacionándolo con el estereotipo de la promiscuidad, enlazado con los miembros de la comunidad LGTBIQ+. Por otro lado, también puede entenderse como que la serie representa la etapa adolescente como un momento vital de exploración sexual, transformación y definición de identidades, como paso previo a la madurez y a su definición como personajes adultos.

Tras comparar las características de estos personajes con los adolescentes heterosexuales de la serie, este estudio concluye que el relato justifica la fugacidad de las relaciones desde la edad de los protagonistas. Sin embargo, los personajes pertenecientes a la comunidad LGTBIQ+ muestran mayor apetito sexual que los personajes heterosexuales, rasgo que también podríamos calificar como tópico. Los personajes pertenecientes al colectivo reflejados en las producciones propias de Netflix mencionadas con anterioridad manifiestan, de forma general, estos rasgos caracterizadores.

El resto de características de la dimensión social de los personajes son comunes, al tratarse de jóvenes adolescentes cuyo estado civil es soltero, no tienen hijos y su ocupación laboral o formativa pasa necesariamente por su experiencia en el instituto, al margen de que algunos de ellos tienen ocupaciones paralelas parciales en un negocio. A excepción de un personaje (Ola Nyman), los personajes, formen o no parte del colectivo, pertenecen a la clase media. Las variables sociales, en definitiva, ofrecen poca variedad dada la uniformidad de situaciones sociales que representan los adolescentes de la serie.

Las actitudes, las formas de afrontar los problemas, las temáticas y los respectivos conflictivos asociados son diferentes entre los personajes. Entre los temas y los conflictos tratados en Sex Education, destacan la homofobia, la introspección, el desarrollo personal, la denuncia del sexismo, los problemas de aceptación de las identidades queer y las distintas formas de abordar esta situación, la experimentación con el sexo. Destacamos la agresividad de Adam, la frialdad de Lily, la naturalidad de Ola y el deseo de libertad de Eric. Aunque los personajes comparten su disidencia con patrones de identidad normativos, sus caracterizaciones son muy diferentes en cuanto a actitudes, temperamentos, temas y conflictos. Ello nace de la marcada y diferenciada identidad con que es configurado cada personaje y de la voluntad de representación de la diversidad que pretende hacer la serie analizada. 
Cabe destacar la confrontación entre los adolescentes y sus progenitores a causa de su sexualidad. Las razones de estos problemas están relacionadas con las temáticas abordadas, como la confrontación entre identidad de género y sexualidad y religión (Eric), o la rigidez y el autoritarismo en las relaciones entre padres e hijos (Adam).

Este trabajo analiza cinco personajes de los ocho adolescentes pertenecientes al colectivo LGTBIQ+ representados en la serie. Incluyendo las categorías de los tres personajes no analizados, aparecen tres personajes homosexuales masculinos (Eric, Rahim y Anwar), dos personajes homosexuales femeninos (Tanya y Ruthie), dos personajes bisexuales de distinto género y sexo (Lily y Adam) y un personaje pansexual (Ola). Apuntemos que los personajes homosexuales no manifiestan dudas con respecto a su identidad, pero esta cuestión resulta más compleja en los personajes bisexuales o en el personaje pansexual, por cuanto no se sienten identificados con identidades que podría interpretar como normativas o aceptadas socialmente, homosexual/heterosexual. Es en la exploración de identidades de género fuera de los márgenes normativos en personajes adolescentes donde la serie encuentra su valor y su originalidad. En todo caso, como hemos comentado, aunque estas tramas tienen un peso relevante en el conjunto del relato, no implican directamente a los protagonistas heterosexuales.

\section{Conclusiones}

Los resultados del análisis confirman la hipótesis de partida, pero requieren de una explicación. Consideramos que la creación de personajes en la serie Sex Education desde identidades queer responde a necesidades de la acción dramática: las cuestiones sobre identidad y la fluctuación entre diversas condiciones sexuales procura el conflicto, como base de articulación narrativa del drama. El conflicto surge, además, de la inestabilidad de las relaciones que establecen los personajes, aspecto que nace del desarrollo del personaje desde su dimensión social, pero también desde su identidad de género y de su orientación sexual. Como en los melodramas clásicos (PérezRufi, 2017), la base del conflicto se encuentra en las cuestiones ligadas a la personalidad de los caracteres y en su evolución, así como en el conflicto que surge a raíz de la interrelación entre personajes con objetivos contrapuestos o cambiantes.

Sex Education es, en principio, una serie cómica en la que la acción y el drama gira alrededor de las experiencias y los dilemas de los personajes en materia de sexo, razón que explica su progresiva aproximación al terreno del melodrama y a la exploración de los conflictos internos de los personajes. Es por esta razón que los personajes inicialmente son estereotipos y ganan después en profundidad psicológica con el desarrollo de tramas más complejas. Estas tramas, como hemos apuntado, están ligadas a cuestiones de género, identidad y orientación sexual. Los personajes se definen a través de una sexualidad conflictiva que les genera inquietudes y problemas en su 
cotidianeidad. El amplio abanico de representaciones de género de la serie permite así un espectro más amplio de tramas alrededor de cuestiones de sexo y género y los personajes LGTBQ+ queda así al servicio del desarrollo de la acción, sirviéndose de estas configuraciones queer como recursos dramáticos.

La variedad y diversidad de identidades queer representadas queda constatada, siendo una de las líneas temáticas principales de la obra. Los estereotipos y las fórmulas y temáticas propios de la comedia de adolescentes están presentes inicialmente; sin embargo, los estereotipos van cayendo conforme se desarrolla la trama. Ello se debe al incremento de información acerca de los personajes y de la suma de características que contrastan con los motivos estereotipados con los que inicialmente son presentados. De esta forma, los condicionantes procedentes del género de la comedia adolescente son progresivamente arrinconados. La segunda temporada de la serie hace una representación de los personajes más compleja, como caracteres redondos que van dejando atrás los motivos estereotipados desde los que inicialmente habían sido definidos.

Temas como el empoderamiento femenino, el apoyo hacia colectivos invisibilizados, la igualdad de género, la violencia y la discriminación en el entorno escolar, el miedo a pertenecer a un grupo aislado o ser diferente, la inclusión y la amplitud del espectro LGTBIQ+ implica a variados personajes de la serie. En todo caso, la representación de esta realidad es parcial. Por ejemplo, están ausentes temáticas que cuestionen las identidades trans desde perspectivas feministas, o el tratamiento de las identidades LGTBIQ+ en países o entornos restrictivos en estos aspectos.

Con el fin de analizar la representación de la comunidad LGTBIQ+ en los contenidos producidos por las industrias culturales, este trabajo invita a ampliar el espectro del objeto de estudio desde a producciones audiovisuales protagonizadas por adolescentes en otros géneros o formatos. Ante el imparable desarrollo de los paradigmas de género y la modificación de los parámetros sociales, no podemos dejar de preguntarnos por las futuras tendencias en la representación de las identidades queer.

\section{Contribución específica y orden de autoría en el artículo}

En este trabajo Águeda María Valverde-Maestre se ocupó de la selección del objeto de estudio, el planteamiento metodológico y el análisis de los personajes, con sus respectivas tablas, además de la redacción de parte de la introducción y de parte del marco teórico. José Patricio Pérez-Rufi se ocupó de la redacción de parte de la introducción y parte del marco teórico, además de la redacción de la discusión de resultados y de las conclusiones, a partir de los resultados obtenidos por el análisis de la investigadora. Ambos investigadores revisaron la redacción y unificaron estilos para darle continuidad y coherencia al desarrollo del texto. Igualmente, se ocuparon de la ade- 
cuación a las modificaciones solicitadas por las revisiones de forma conjunta. Águeda María Valverde-Maestre firma como primera autora del texto como responsable de la iniciativa en este trabajo y como orientadora del planteamiento metodológico y de la investigación, a la que se incorporó José Patricio Pérez-Rufi siguiendo sus directrices y aportando su experiencia con la investigación en cuestiones de narrativa audiovisual.

\section{Referencias bibliográficas}

Basté, C. y Peralta, M. (2016). Sorprender cada minuto y medio: El guión en la televisión de entretenimiento y actualidad. Barcelona: UOC.

Butler, J. (2007). El género en disputa. El feminismo y la subversión de la identidad. Barcelona: Paidós.

Casetti, F. y Di Chio, F. (1990). Cómo analizar un film. Barcelona: Paidós.

Collin, F. (2010). Des lumieres a la Queer Theory en France ou de l'individu au trans-genre. Investigaciones feministas, 1, 177-191. Recuperado de https://tinyurl.com/y58nnrvr

Lauretis, T.D. (1991). Queer Theory. Lesbian and Gay Sexualities. Differences: A Journal of Feminist Cultural Studies. Bloomington: Indiana University Press.

Egri, L. (1946). The art of dramatic writing. Nueva York, Simon \& Schumster.

Federación de Cines de España (FECE) (2019). Las salas de cine han invertido más de 400 millones de euros en la adaptación de nuevas tecnologías e implantación de nuevos formatos. FECE, 10/09/2020. Recuperado de https://tinyurl.com/yxhhv8bs

Galán-Fajardo, E. (2006). Personajes, estereotipos y representaciones sociales. Una propuesta de estudio y análisis de la ficción televisiva. Revista ECO-PÓS, 9(1), 58-81. Recuperado de https://cutt.ly/1fxPHhD

Galán-Fajardo, E. (2007). Fundamentos básicos en la construcción del personaje para medios audiovisuales. Enlaces: revista del CES Felipe II, 7. Recuperado de https://tinyurl.com/ y6a6nugl

Guarinos-Galán, V. (2009). Fenómenos televisivos teenagers: prototipias adolescentes en series vistas en España. Comunicar, 33(17), 203-211. https://doi.org/10.3916/c33-2009-03-012

Hernández Escorcia, R.D. (2020). Disforia de género infantil. Una reflexión ética a partir de la vulnerabilidad, la responsabilidad y la beneficencia en Colombia. Revista Iberoamericana de Bioética, 12, 1-12. https://doi.org/10.14422/rib.i12.y2020.009

López Gutiérrez, M.L. y Nicolás Gavilán, M.T. (2015). El análisis de series de televisión: construcción de un modelo interdisciplinario. Revista ComHumanitas, 6(1), 22-39. Recuperado de https://tinyurl.com/y2azrmej

López Rodríguez, F.J. (2011). Nerds y geeks como protagonistas de las nuevas sitcoms. Estudio de los personajes principales de The IT Crowd y The Big Bang Theory. En M.A. Pérez Gómez (coord.) Previously on: estudios interdisciplinarios sobre la ficción televisiva en la Tercera Edad de Oro de la Televisión (pp. 807-820). Sevilla: Universidad de Sevilla. 
Martínez, A. (2015). Apuntes sobre el cuerpo en el pensamiento de Judith Butler. Aportes del psicoanálisis en la Teoría Queer. Affectio Societatis, 12, 23, 1-16. Recuperado de https://tinyurl.com/y5sofjvm

Mayorga Escalada, S. (2019). Netflix, estrategia y gestión de marca en torno a la relevancia de los contenidos. adComunica, 18, 219-244. http://dx.doi.org/10.6035/2174-0992 .2019.18.11

Pelayo García, I. (2011). Performance drag y parodia en Tacones Lejanos. Icono 14, 9, 160 176. https://doi.org/10.7195/ri14.v9i3.105

Pereira Domínguez, M.C. (2009). Cine, cárcel y mujeres. Un ejemplo de creación de conocimiento.Enl@ce, 6 (2), 39-55. Recuperado de https://tinyurl.com/y55yg6rk

Pérez Lence, F. (2019). Sex Education: La ESI en Netflix. Comunicación y género, 2(1), $121-$ 134. https://dx.doi.org/10.5209/CGEN.64528

Pérez-Rufi, J.P. (2017). El género cinematográfico como elemento condicionante de la dimensionalidad del personaje del cine clásico de Hollywood: características de los personajes cinematográficos redondos y planos. Admira, 5, 1-33. https://idus.us.es/ handle/11441/76046

Raya, I., Sánchez Labella, I. y Durán Manso, V. (2018). La construcción de los personajes protagonistas en las series de Netflix Por trece razones y Atípico. Comunicación y Medios, 27(37), 131-143. https://doi.org/10.5354/0719-1529.2018.48631

Ríos San Martín, M. (2012). El guion para series de televisión. Madrid: IORTV.

Solana, M.N. (2013). La Teoría Queer y las narrativas progresistas de identidad. La ventana, 4 (37), 70-105. Recuperado de https://cutt.ly/8fxV3Bw

Toledano, G. y Verde, N. (2007). Cómo crear una serie de televisión. Madrid: T\&B Editores.

Tovar, M. (2019). Discurso del capitalismo y el sujeto queer. Revista Venezolana de Estudios de la Mujer, 24(52-53), 65-79. Recuperado de https://tinyurl.com/y2haobmq

Valverde-Maestre, A. M. (2019). Los géneros y formatos de éxito en el contexto televisivo español. En J.P. Pérez-Rufi y A. Sosa-Valcarcel (coords.). Industrias audiovisuales: tendencias de producción y consumo (pp. 41-50). Málaga, Eumed.net. Recuperado de https:// tinyurl.com/yysktqm6

Zurian-Hernández, F. Y Herrero-Jiménez, B. (2014). Los estudios de género y la teoría filmica feminista como marco teórico y metodológico para la investigación en cultura audiovisual, Área Abierta, 14(3), 6-21. Recuperado de https://cutt.ly/bfxBkPP 